\title{
Endoscopic Resection of a Large Esophageal Leiomyoma
}

We report here the case of a 46-year-old man in whom a large tumor was detected in the lower third of the esophagus. Endoscopic ultrasonography (EUS) showed that the tumor originated in the muscularis mucosae and that the submucosa was intact.

The tumor was a leiomyoma, which is one of the benign tumors frequently observed growing intramurally, and which is usually located in the lower esophagus $[1,2]$. Although the lesion was approximately $4 \times 4 \times 2 \mathrm{~cm}$ in size (Figure 1 ), and was initially regarded as too large for endoscopic mucosal resection (EMR), it was decided to treat it using EMR, based on the EUS findings and normal laboratory tests [3-5]. The tumor was successfully resected, and the mucosal defects were repaired by applying six clips (Figure $1 \mathbf{c}$ ). The patient tolerated the procedure well, and made a good recovery. The resected specimen was $2 \mathrm{~cm}$ thick, covered with
If accurate EUS information is available, EMR may be a feasible method of managing esophageal tumors, even when they are up to $4 \mathrm{~cm}$ in size. The mucosal defect can be immediately repaired using the clipping technique, with clips applied to the anal and oral ends of the defect.

\section{J. B. Chen ${ }^{1}$, T. Kudzu², E. Hishikawa ${ }^{2}$, S. Miyazaki ${ }^{2}$ \\ ${ }^{1}$ Dept. of Surgery, Taichung Veterans' General Hospital, Taiwan, \\ Republic of China \\ ${ }^{2}$ Dept. of Endoscopic Diagnostics and Therapeutics, Chiba University School of Medicine, Chiba, Japan}

\section{References}

${ }^{1}$ Seremitis MG, Lyos WS, DeGuzman VC, Peabody JW. Leiomyoma of the esophagus. Cancer 1976; 38: 2166-2175

${ }^{2}$ Redina EA, Venuta F, Pescamona EO et al. Leiomyoma of the esophagus. Scand J Thorac Cardiovasc Surg 1990; 24: 79 82
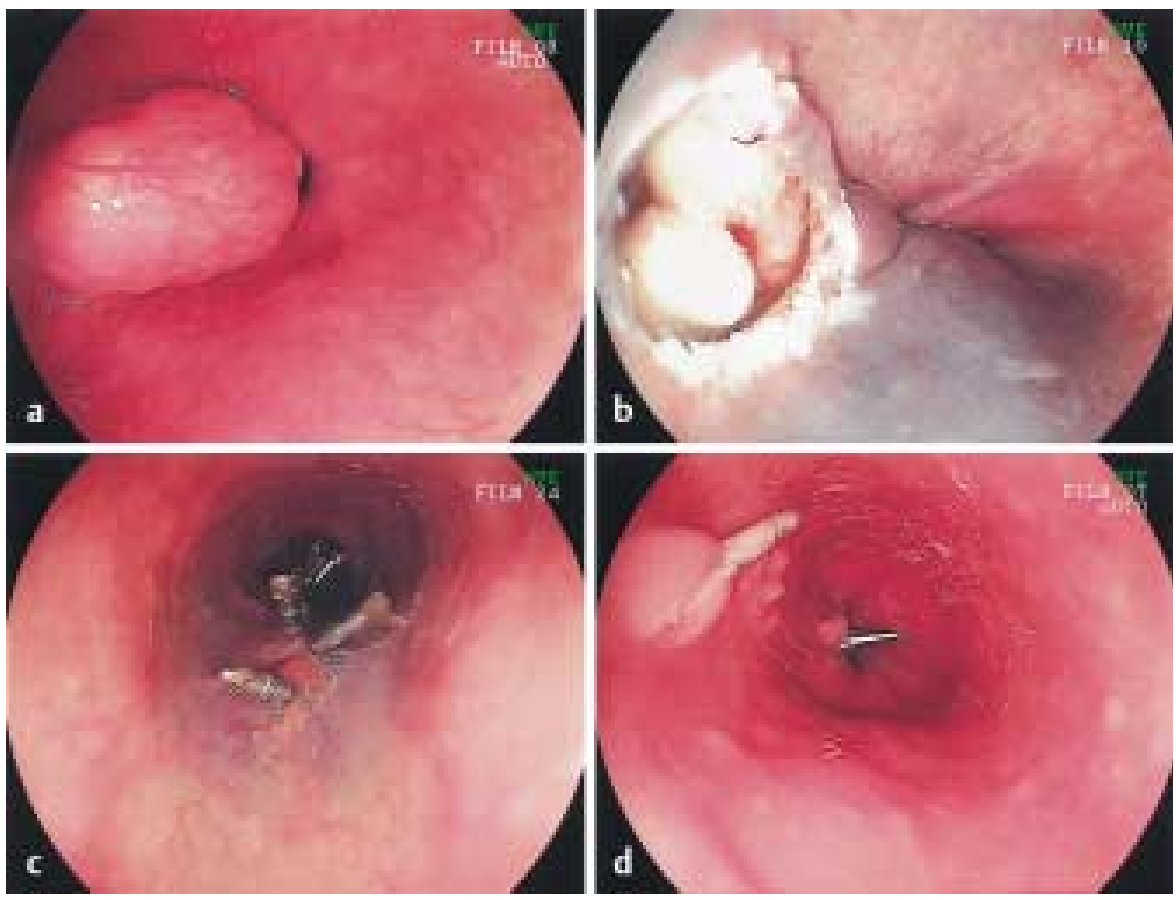

Figure 1 A well-vascularized submucosal tumor with a smooth surface, detected in the lower third of the esophagus. a Endoscopic findings. b After endoscopic mucosal resection. c Closure of the mucosal defect using clips. $\mathbf{d}$ The appearance of the site 6 weeks after resection
${ }^{3}$ Robinson AS, Sommer DA, Levinson M. Transfiberscopic removal of esophageal polyps. Am J Gastroenterol 1974; 61: $297-300$

${ }^{4}$ Eda Y, Asaki S, Yamagata L et al. Endoscopic treatment of submucosal tumors of the esophagus: studies in 25 patients. Gastroenterol Jpn 1986; 148: 901

${ }^{5}$ Hynn JH, Jeen YT, Chun HJ et al. Endoscopic resection of submucosal tumor of the esophagus: results in 62 patients. Endoscopy 1997; 29: 165 - 170

\section{Corresponding Author}

\section{T. Kudzu, M.D.}

Dept. of Endoscopic Diagnostics and Therapeutics

Chiba University School of Medicine 1-8-1 Inohana, Chuo-ku Chiba 260-28777, Japan

Fax: + 81-43-226-2368

E-mail: kouzut@ho.chiba-u.ac.jp 